\title{
Desenvolvimento de uma nova versão de escala para mensuração das características que incentivam a adoção de novos produtos: um estudo sobre a água mineral
}

\begin{abstract}
RESUMO
Entre 1974 e 2003, o Instituto Brasileiro de Geografia e Estatística constatou que a água mineral foi o produto que apresentou maior crescimento em seu consumo por parte das famílias brasileiras, sendo que entre 2003 e 2009 o aumento foi de 300\%. Este trabalho se atém a um dos itens do Modelo de Difusão de Inovações de Rogers - a inovação -, a qual preconiza que os fatores comunicabilidade, complexidade, compatibilidade, divisibilidade e vantagem relativa, facilitariam o processo de adoção de novos produtos pelos consumidores. O objetivo deste trabalho foi o de refinar a primeira versão da escala de adoção de novos produtos baseada no Modelo de Difusão de Inovações, verificando se ela possui validade nomológica e medir a variância explicada do comportamento passado frequente dos indivíduos em relação ao consumo de água mineral, além da inclusão do construto envolvimento e sua influência sobre o modelo e a escala refinada. Esta é uma pesquisa descritiva e a amostra é formada por alunos universitários. Foi realizado o pré-teste e obteve-se 318 questionários considerados válidos. Após o exame dos dados, a amostra ficou composta por 273 casos. Apesar de alcançar bons níveis de unidimensionalidade, confiabilidade interna, validade convergente e discriminante, somente um dos construtos da escala (vantagem relativa) apresentou relação significativa com a frequência de ingestão de água mineral. Apesar de apresentar relação significativa com o comportamento passado, a inclusão do construto envolvimento não alterou as relações dos outros construtos, e nem a variância explicada para o consumo de água mineral.
\end{abstract}

Palavras-chave: Gestão de produtos. Modelo de Difusão de Inovações. Desenvolvimento e teste de escala. Adoção de novos produtos. Água mineral.

Luiz Rodrigo Cunha Moura luizcrmoura@gmail.com Mestre em Administração Centro Universitário UMA

Nina Rosa da Silveira Cunha ninarosa@ufv.br

Doutora em Economia Rural Universidade Federal de Viçosa

Giovanni Duarte Porto innavoig.comex@gmail.com Bacharel em Administração Centro Universitário UMA

Luiz Eduardo Leite de Moura prof.lelmoura@gmail.com Mestre em Administração Universidade Presidente Antônio Carlos

Ruthe Rebello Pires ruthepires@yol.com.br Mestra em Eficiência Energética Centro Universitário UMA 


\section{INTRODUÇÃO}

Verifica-se atualmente um fenômeno no Brasil: o grande crescimento do consumo de água mineral, o qual de acordo com dados do IBGE - Instituto Brasileiro de Geografia e Estatística, por meio da sua pesquisa de orçamentos familiares (POF), constatou que o consumo de água mineral saltou entre 1974 e 2003 de 0,3 kg para 18,5 kg per capita por ano (IBGE, 2004). Assim, de acordo com o IBGE (2004), a água mineral foi o produto que apresentou maior crescimento em seu consumo por parte das famílias brasileiras.

A produção ou envasamento de água mineral teve por objetivo cuidar da saúde das pessoas. As águas medicinais fizeram muito sucesso ao longo do tempo no Brasil, haja vista que até mesmo houve o turismo medicinal, o qual foi desenvolvido por diversas cidades que possuíam fontes de água mineral com altas composições de sais minerais. Ao mesmo tempo, se procurou envasar essas águas em frascos, para que as mesmas pudessem ser transportadas para locais mais distantes e que pessoas que não tivessem condições de se locomover até as suas fontes, pudessem também tomar dessas águas. O surgimento das marcas e o crescimento desse negócio foi somente uma questão de tempo. Logo surgiram máquinas capazes de aumentar a produção e concomitantemente, os meios de transporte também evoluíram, tornando a distribuição desse produto mais fácil, bem como o acesso dos consumidores (MACEDO, 2001). No final da década de 60, ocorreu o lançamento do garrafão de vidro de 20 litros, que mais tarde, na década de 70, foi substituído pelo garrafão de plástico, também de 20 litros. Isso causou um grande aumento no consumo de água mineral, a qual pode ser transportada em grandes volumes dentro dos centros urbanos (BUZZETTI, 1998).

De acordo com Departamento Nacional de Produção Mineral (DNPM), o Brasil é o quarto maior mercado consumidor mundial de água mineral, tendo consumido em 2012 cerca de 17,5 bilhões de litros (ASSIRATI, 2013). Dados da Associação Brasileira da Indústria de Águas Minerais (VERÃO..., 2014) descrevem que em 2014, a previsão de faturamento do setor é de 2 bilhões de reais.

O objetivo deste estudo é desenvolver uma nova versão da escala para representar os fatores presentes na teoria para mensurar a percepção dos consumidores em relação a um determinado produto ou serviço e testá-la usando os fatores presentes na adoção de novos produtos - no caso desta pesquisa, a água mineral. A escala usada neste trabalho é uma segunda versão, baseada na primeira versão elaborada por Moura et al. (2008), a partir da teoria desenvolvida por Rogers (1983). Além disso, têm-se como objetivos específicos:

- Identificar quais os construtos sobre a adição de novos produtos são mais importantes em relação ao consumo de água mineral.

- Verificar a confiabilidade interna, validade de conteúdo, validade convergente e validade discriminante de cada um dos construtos que compõem a escala, ou seja, a sua validade nomológica.

- Verificar se a adição do construto envolvimento aumenta a variância explicada para a frequência de beber água mineral, além de também possuir validade nomológica.

A questão básica a ser respondida por este trabalho é: a nova versão da escala criada para representar os fatores presentes na teoria para mensurar a percepção dos consumidores em relação a um determinado produto ou serviço, possui validade nomológica?

Entre as justificativas para a realização desta pesquisa, podem-se destacar a importância do estudo do comportamento do consumidor, considerado o seu processo de compra, a sua avaliação e percepção através dos atributos dos produtos e suas principais dúvidas. Além disso, em termos sociais essa compreensão é muito útil tanto para o governo, quanto para aquelas organizações do terceiro setor, que desejam promover tanto a produção quanto a comercialização desse tipo de produto para todos os setores da nossa sociedade, colaborando para uma melhoria da qualidade de vida da mesma como um todo.

Outro ponto ressaltado é que a compreensão acerca das escolhas e comportamento de consumo são assuntos altamente estudados pelos pesquisadores de marketing. Um dos modelos mais difundidos é o trabalho de Rogers (1983), denominado Modelo de Difusão de Inovações. Este trabalho se atém a um dos itens deste modelo - a inovação -, a qual preconiza que os fatores comunicabilidade, complexidade, compatibilidade, divisibilidade e vantagem relativa seriam capazes de facilitar o processo de adoção de novos produtos por parte dos consumidores. Por conseguinte, a contribuição teórica deste trabalho é a de aprimorar 
a primeira versão da escala de adoção e difusão de novos produtos baseada neste modelo, bem como verificar se a adição de um novo construto - envolvimento com o produto - apresenta resultados melhores do que a escala que contempla os cinco construtos definidos por Rogers (1983).

Cabe ressaltar ainda a abordagem diferenciada deste tipo de escala no Brasil. Obviamente existem estudos relacionados à adoção e difusão de novos produtos, mas muitos deles se atém à aceitação de tecnologia utilizando modelos como o TAM, por exemplo (GROHMANN et al., 2010), o papel da confiança da marca na adoção de novos produtos (TERRES et al., 2010), outros ainda trabalham aspectos organizacionais, dos clientes e do ambiente externo (governo, tecnologia, etc.) (DE TONI; MILAN; REGINATO, 2011; URDAN; OSAKU, 2005).

\section{REVISÃO TEÓRICA}

Este capítulo apresenta a literatura que deu suporte para o desenvolvimento deste trabalho.

\subsection{Adoção e Difusão de um Novo Produto}

É importante conhecer e entender o processo de adoção (decisões individuais que a pessoa toma antes de aceitar um produto) e difusão (processo de divulgação do novo produto na sociedade) de um novo produto pelo possível cliente (ETZEL; WALKER; STANTON, 2001), lembrando que o processo de adoção por parte do consumidor começa quando se encerra o processo de inovação por parte da empresa. De acordo com a visão dos consumidores, um novo produto é aquele que é percebido como diferente quando comparado com os produtos atuais (BLACKWELL; MINIARD; ENGEL, 2005).

Conforme Sheth, Mittal e Newman (2001), o processo de adoção é dividido em quatro etapas: consciência, interesse, desejo e ação. Nesse caso, o consumidor passa por esses quatro estágios, os quais possuem uma hierarquia. Assim, em um primeiro momento os consumidores tomam consciência a respeito do novo produto. Em seguida ficam interessados pelos mesmos e posteriormente se sentem atraídos e compram esse novo produto.

O ciclo de vida de um produto vem diminuindo em função do dinamismo e velocidade do mercado. Antigamente, os veículos eram projetados para ficarem cerca de dez anos no mercado, hoje novos modelos são lançados a cada dois anos, o que significa que possíveis clientes devem ser rapidamente identificados para o início, meio e fim do ciclo de vida do produto. As inovações são classificadas em relação ao comportamento dos consumidores em três categorias (SOLOMON, 2002; BLACKWELL; MINIARD; ENGEL, 2005):

- Inovação Contínua: são pequenas modificações que ocorrem nos produtos atuais. Caracterizam-se por serem simples extensões de linha, oferecendo novas oportunidades de escolha e representam pequenas mudanças nos hábitos de consumo.

- Inovação Dinamicamente Continua: significa uma mudança mais pronunciada do que a inovação contínua e que influencia nos hábitos de vida e no manuseio dos produtos.

- Inovação Descontínua: são produtos que criam grandes mudanças na vida da população. São produtos realmente inovadores - e não simplesmente uma versão melhorada dos produtos atuais no sentido de que substituem de forma plena os produtos anteriores.

Em relação ao caráter revolucionário dos produtos, segundo Aggarwal, Cha e Wilemon (1998) quanto maior o nível de ruptura dos novos produtos, pior tende a ser sua avaliação pelos consumidores. Isto explica porque alguns produtos em um primeiro momento são mal avaliados e, com o passar do tempo, são melhor avaliados pelo público e consumidos em maior ou larga escala. Além disso, uma grande ruptura torna o processo de busca de informações por parte dos consumidores mais lento, incerto e trabalhoso.

\subsection{O modelo de Difusão de Inovações}

O Modelo de Difusão de Inovações (MDI) está relacionado em como as inovações, sejam elas ideias ou atividades, são consideradas como algo realmente novo e são difundidas em um grupo social por meio de canais de comunicação (ROGERS, 1983). 
Este modelo está dividido em quatro grupos principais:

a) A inovação, onde algumas características influenciam diretamente a velocidade na qual uma inovação vai ser difundida: a existência de grandes vantagens em relação ao antigo; se o novo é compatível com as crenças e valores dos indivíduos; a facilidade de entendimento, compreensão e adaptação por parte dos indivíduos; se o novo é observável ou tangível; e, se o novo pode ser dividido para ser melhor compreendido (ROGERS et al., 2008).

b) Os canais de comunicação, que correspondem aos meios pelos quais as informações são transmitidas de um indivíduo para o outro. A utilidade dos diferentes canais de comunicação depende do objetivo específico da comunicação. No caso de mudança de crenças e atitudes em relação à inovação, a comunicação interpessoal em geral apresenta melhores resultados, enquanto que para a difusão de inovações, a comunicação de massa é a mais indicada.

c) O tempo influencia e tem três papéis no MDI. Primeiramente é um dos fatores que definem a quantidade de informação a ser buscada por uma pessoa. Além disso, ele influencia na formação das cinco categorias de adotantes (inovadores, adotantes iniciais, maioria inicial, maioria tardia e retardatários). Por fim, ele também possui um papel importante na própria taxa de adoção de novos produtos por meio da velocidade de adoção por parte das pessoas em um período definido de tempo.

d) O sistema social. A sua própria estrutura (grupos organizados ou informais, por exemplo) e as suas normas internas, influenciam na velocidade, tempo e processo de adoção de novas ideias ou práticas dentro de um sistema social formado por várias unidades com o intuito de atingir o mesmo objetivo. Dentro do grupo Inovação, existem cinco características que podem afetar o processo de adoção ao novo produto, principalmente se ele for uma inovação no mercado (ROGERS, 1983; GUPTA; ROGERS; 1991; PETER; OLSON, 1999). São elas:

- Vantagem relativa: Grau de vantagem que uma inovação oferece em relação aos produtos disponíveis no mercado, formada pelos consumidores ao comparar os novos produtos com os já existentes tem grande influência na taxa de adoção. Esta vantagem pode estar presente no custo mais baixo, segurança oferecida, facilidade de uso, etc. Para Blackwell, Miniard e Engel (2005) e Solomon (2002), esta é a mais importante característica que os novos produtos devem ter em relação aos convencionais.

- Compatibilidade: Grau em que o produto é compatível com os valores e experiências dos indivíduos da comunidade. A incompatibilidade pode surgir quando os produtos utilizados atualmente não atendem as necessidades e expectativas dos consumidores (AGGARWAL; CHA; WILEMON, 1998).

- Complexidade: Pode ser entendida como o grau de dificuldade que os consumidores sentirão para utilizar o novo produto, isto significa que quanto mais complexo o produto for percebido pelos clientes, mais demorada será a sua adoção. Em países onde o nível de educação e/ou alfabetização é baixo, a alta complexidade percebida pelo público-alvo pode diminuir a taxa de adoção de alguns produtos. Equipamentos eletrônicos têm problemas em relação a esta característica, uma vez que a dificuldade em entender e/ou utilizar um novo produto pode atrapalhar sua adoção pelos consumidores. A dificuldade e o nível técnico das instruções contidas nos manuais dos novos produtos também são importantes para a formação dessa característica.

- Possibilidade de experimentar (divisibilidade): Caracteriza-se pela capacidade de um novo produto ser experimentado com pouco esforço (tempo, recursos financeiros, conhecimento e afins). Geralmente os produtos mais caros têm taxa de adoção menor ou mais lenta por causa desta característica, ou seja, quanto maior a possibilidade do cliente experimentar e testar um novo produto, desconsiderando as outras características, melhor será seu percentual de adoção. As amostras grátis são um ótimo instrumento para auxiliar na experimentação por parte dos clientes.

- Comunicabilidade: Expor um produto em funcionamento aumenta a taxa de adoção. Se os resultados do uso do novo produto são facilmente identificados pelos indivíduos, e comunicados pelos mesmos, então a possibilidade de sucesso de novo produto é bem maior. É importante identificar o nível de percepção dos benefícios de um novo produto por parte do seu mercado potencial.

Ainda em relação às características que afetam o processo de adoção de novos produtos... 
Os mesmos fatores que influenciam o provável sucesso de uma inovação também influenciam a rapidez com a qual ela é adotada. O produto será adotado mais rapidamente à medida que satisfizer uma necessidade, for compatível, tiver uma vantagem relativa, for menos complexo, tiver aspectos positivos notáveis e puder ser facilmente experimentado (MOWEN; MINOR, 2003, p. 286).

De acordo com Sheth, Mittal e Newman (2001), as principais resistências às inovações são o hábito e o risco. Em relação ao primeiro, pode-se considerar que o consumidor age de uma determinada maneira, aprendida anteriormente, sempre que se encontra na mesma situação anterior ou é estimulado da mesma forma novamente.

Em relação aos riscos são percebidos como algo que pode dar errado ou como consequências indesejáveis de uma ação de compra e utilização dos produtos. Os mesmos foram classificados como riscos de desempenho, onde os produtos não apresentam o desempenho anteriormente previsto por parte dos consumidores. Além disso, têm-se também os riscos sociais, ou seja, a preocupação com a opinião e aprovação dos indivíduos que formam a sociedade, classes sociais, família, grupos de convívio e afins, nos quais o consumidor pertence ou se relaciona (SHETH; MITTAL; NEWMAN, 2001).

Outro aspecto destacado por Aggarwal, Cha e Wilemon (1998) é que as novas tecnologias são vistas pelos consumidores como um fator de risco. Obviamente, quanto maior o risco percebido, maior será a dificuldade de adoção de novos produtos. Além disso, estes autores observam que a adoção de novos produtos requer uma aprendizagem dos consumidores acerca dos mesmos (às vezes requer até mesmo um grande esforço cognitivo). Assim, a possibilidade do cliente experimentar um produto pode ser fundamental para que o consumidor possa conhecê-lo melhor. Outro ponto a ser considerado é que a comunicabilidade também é fundamental para que o público-alvo não só possa receber a informação pertinente, mas também tenha condições de compreendê-la e memorizá-la.

Além disso, Chao e Gupta (1995) e Ahmed et al. (2004) descrevem a importância do país de origem do produto. Esse fator, de acordo com estes pesquisadores influencia fortemente a taxa de adoção de produtos estrangeiros em novos mercados e as crenças, percepções e atitudes dos consumidores em relação ao seu país de origem.

Em termos gerais, a inovação pode ser entendida como um processo que envolve diversos fatores, tais como pessoas, estrutura, estratégia, processos e tecnologia, as quais devem ser coerentes com as demandas do mercado facilitando o seu processo de adoção por parte do seu público-alvo (PAREDES; SANTANA; FELL, 2014).

\subsection{Envolvimento}

O significado do conceito de envolvimento possui diferentes conteúdos entre os estudiosos. Isso se deve ao fato de que o próprio construto nível de envolvimento ser utilizado em aplicações distintas, o que gera diferenças conceituais. Essas aplicações são basicamente: envolvimento com a publicidade ou propaganda, envolvimento com os produtos e envolvimento com a decisão de compra. De acordo com Zaichkowsky (1985), independentemente do contexto utilizado, a construção de uma medida de envolvimento deve captar as diferenças entre os indivíduos (interesses, valor e necessidades perante o objeto), objetos (características distintivas) e situações (fatores temporais que aumentam ou diminuem a relevância perante o objeto). Assim, diferenças no envolvimento com os produtos, fazem com que as pessoas prestem mais atenção, criem maior importância e se comportem de forma diferente no processo decisório, na escolha dos produtos nas mensagens de comunicação, etc. (ZAICHKOWSKY,1986). Nesta pesquisa, é utilizado o mesmo conceito de Zaichkowsky (1985), o qual foi usado para a criação de uma escala de mensuração das atitudes. Assim, envolvimento é "a percepção de uma pessoa a respeito da relevância de um objeto baseado nas suas necessidades, valores e interesses inerentes" (ZAICHKOWSKY,1985, p. 342).

Zaichkowsky (1990) criou outra versão da escala, desta vez com dez opções. Havia muitos itens redundantes. Portanto, para medir o envolvimento, os dez itens gerados seriam suficientes. Em 1995, Mittal realizou um teste com a adaptação de quatro escalas diferentes, entre elas a de Zaichkowsky. Os resultados foram animadores, sendo que essa escala adaptada apresentou os maiores níveis de confiabilidade interna e de explicação da variância. 


\section{METODOLOGIA}

Os procedimentos metodológicos estão caracterizados nas seções seguintes deste capítulo.

\subsection{Atividades de Pesquisa}

Esta é uma pesquisa descritiva, pois é um tipo de pesquisa cujo maior objetivo é a descrição de algo, em geral características de mercado ou funções (MALHOTRA, 2011).

Para a realização da pesquisa, foi realizado um survey com os consumidores de água mineral. Para a elaboração do questionário, foi considerada a primeira versão da escala de adoção de novos produtos (MOURA et al., 2008) e realizado um refinamento baseado nos conceitos presentes na Teoria da Difusão de Inovações (ROGERS, 1983).

Após a elaboração do instrumento de coleta dos dados, foi realizado o pré-teste do questionário junto ao público-alvo da pesquisa. Os resultados além de servirem de embasamento para alterações e melhorias no questionário original, também foram utilizados para o cálculo do tamanho representativo da amostra. Assim, foram aplicados 35 questionários, com o intuito de se identificar os problemas e pontos duvidosos que os mesmos apresentavam para os respondentes. Foram seguidas as técnicas recomendadas por Malhotra (2011) que descreve que o propósito do pré-teste é o de melhorar o questionário pela identificação e eliminação de problemas em potencial. O pré-teste deve ser realizado junto ao mesmo público-alvo da pesquisa, ou seja, a amostra do pré-teste deve possuir as mesmas características da amostra a ser pesquisada.

As unidades de observação são os alunos de um Centro Universitário. As unidades de análise são os consumidores brasileiros de água mineral. A aplicação dos questionários, bem como as entrevistas, ocorreram em uma metrópole da região sudeste do Brasil. Contudo, apesar da unidade de análise se referir aos consumidores brasileiros, a amostragem utilizada não foi probabilística, pois, a mesma não garante a completa aleatoriedade dos dados obtidos. Assim, essa amostra é classificada como por conveniência, a qual segundo Malhotra (2011) é uma amostragem não probabilística, em que a seleção das unidades amostrais é baseada na obtenção de elementos convenientes, ou seja, eles estão no lugar adequado no momento oportuno. É a mais rápida e mais barata, pois os elementos são fáceis e rápidos de encontrar. Foram recolhidos no total 318 questionários respondidos pelos estudantes.

\subsection{Alterações Efetuadas no Conteúdo da Escala}

A seguir estão descritas as mudanças feitas na escala para avaliar a adoção dos consumidores em relação à água-mineral, em comparação com a primeira versão da escala (MOURA et al., 2008):

- Tornou-se os enunciados dos itens mais padronizados de forma a poderem ser utilizados de maneira mais simples para qualquer tipo de produto e serviço de forma fácil e com a menor possibilidade de modificações.

- Todas as dimensões passaram a serem representadas pelo mesmo número de questões - quatro para cada uma das dimensões teóricas. Por conseguinte, a escala aprimorada possui 20 questões no total, contra 25 questões na pesquisa anterior.

- A dimensão vantagem relativa passou a ter quatro itens ao invés dos cinco anteriores. Assim, foi retirada a questão com o seguinte enunciado "O carro bi-combustível tem vantagens importantes em relação ao carro movido somente à gasolina".

- A dimensão compatibilidade passou de três para quatro itens. Foi adicionada uma questão com o enunciado "Beber água mineral é coerente com o meu jeito de ser".

- Foi modificada uma das questões da dimensão compatibilidade nessa nova versão da escala. $O$ enunciado da pesquisa anterior "A minha personalidade me fez interessar em possuir um carro bicombustível", foi modificado para "A minha personalidade ajuda a me identificar em beber água mineral". A mudança ocorreu com o intuito de aumentar o valor do Alpha de Cronbach, o que é o 
responsável por identificar a confiabilidade interna da escala - obtido na primeira pesquisa.

- A dimensão comunicabilidade passou a ter quatro itens ao invés dos cinco presentes na primeira versão da escala. Foi retirada a questão com o enunciado "Eu conheço as diferenças entre o carro bicombustível e os outros carros". Novamente, a sua escolha deveu-se em função do aumento do valor do Alpha de Cronbach.

- Ainda em relação à dimensão comunicabilidade, foram modificados os itens "existem muitas reportagens em revistas e jornais que ajudam a explicar as diferenças e as vantagens/desvantagens do carro bi-combustível" e "as diferenças que existem entre os carros bi-combustíveis e os carros comuns são amplamente divulgadas pela imprensa" para "é fácil para eu descrever para outras pessoas as vantagens que existem entre a água mineral e a água potável comum" e "é fácil para eu perceber as vantagens que existem entre a água mineral e a água potável comum".

Foi incluída uma questão com o intuito de verificar qual é o nível de importância de cada dimensão de acordo com a percepção dos consumidores. Conseqüentemente, os gestores de marketing terão mais subsídios para tomar decisões relativas aos 4 P's de marketing, baseados na percepção dos consumidores. Assim, essa questão foi organizada de forma que cada respondente terá de avaliar cinco frases, as quais representam cada uma dos cinco fatores que favorecem a adoção de novos produtos. Os respondentes deverão atribuir notas de 0 a 10 pontos para cada afirmativa (fator).

\subsection{Validade do conteúdo}

Uma escala, a qual tenha a finalidade de medir a intensidade ou presença de um determinado construto deve passar por uma avaliação do seu conteúdo, ou seja, avalia-se a correspondência entre os itens - de forma individual - que estão presentes na escala e a sua definição conceitual. Apesar de ser uma atividade bastante subjetiva, na qual o pesquisador verifica se os itens que compõem a escala realmente abrangem todo o seu possível conteúdo, sem faltar algum aspecto importante desse construto. É importante notar que enquanto a confiabilidade se atém a como medir algo - consistência das medidas -, a validade diz respeito ao que deve ser medido - o quanto o conceito é bem definido pelas medidas (HAIR et al., 2009; MALHOTRA, 2011).

Em outras palavras, a validade verifica se as diferenças observadas em relação às mensurações de um determinado objeto realmente refletem as diferenças de opinião ou percepção de diferentes entrevistados, enquanto que a confiabilidade garante que os meios utilizados para a medição do objeto ou construto realmente indicam as diferenças de percepção dos respondentes. A confiabilidade é uma condição necessária, mas ela não garante a existência da validade. Por outro lado, se uma medida é valida, ela então será confiável. Para que o pesquisador possa criar instrumentos adequados à mensuração de fenômenos, é necessário um grande conhecimento a respeito do domínio ou escopo do problema. Além disso, como passo seguinte, esse autor descreve que a formação dos itens que irão compor a escala, a qual deverá capturar as medidas ou valores do construto. Em ambas as atividades, em geral, utiliza-se de pesquisa exploratória por meio da revisão da literatura e meios qualitativos com o público-alvo relacionado com o construto (por exemplo, consumidores, pais, mães, alunos, etc.), professores, especialistas e profissionais do ramo de negócios, se for o caso (CHURCHILL JR., 1979).

Além disso, nesse estudo, foram analisadas as descrições dos fatores que afetam o processo de adoção de novos produtos por parte dos consumidores. Além disso, os enunciados das questões que formam os construtos foram revisados por outros dois professores e especialistas em marketing.

\subsection{Operacionalização dos Construtos}

A teoria da adoção de novos produtos preconiza que existem cinco fatores principais que são os responsáveis pela melhoria na adoção de novos produtos, os quais formaram os construtos - vantagem relativa, compatibilidade, complexidade, divisibilidade e comunicabilidade, os quais foram representados pelas seguintes afirmativas: 
- Vantagem relativa: "A água mineral apresenta vantagens em relação á água potável comum”; "A água mineral é melhor do que a água potável comum"; "A água mineral é superior à água potável comum" e "A relação custo/benefício da água mineral é positiva". Estas afirmativas correspondem às questões $3,11,13$ e 18 , respectivamente.

- Compatibilidade: "Tomar água mineral é compatível com o seu jeito de viver a vida"; "A água mineral é coerente com o meu estilo de vida"; "A minha personalidade ajuda a me identificar em beber água mineral" e "Beber água mineral é coerente com o meu jeito de ser". Estas afirmativas são relativas às questões 2, 6, 16 e 20, respectivamente.

- Complexidade: "A água mineral é um produto que é fácil de entender como utilizá-la"; "A água mineral é um produto que não apresenta dificuldades em usá-la"; "A água mineral é um produto fácil de ser utilizado" e "Beber água mineral é igual a beber a água potável comum". Estas afirmativas correspondem às questões $9,10,12$ e 17 , respectivamente.

- Divisibilidade: "A água mineral é fácil de ser experimentada"; "A água mineral é um produto fácil de testar antes de comprá-la"; "Na hora da compra, é fácil provar a água mineral" e "É fácil conhecer a água mineral antes de comprá-la no ponto de venda". Estas afirmativas correspondem às questões 1 , 4, 8 e 19 , respectivamente.

- Comunicabilidade: "É fácil para eu descrever para outras pessoas as vantagens que existem entre a água mineral e a água potável comum"; "É fácil para eu perceber as vantagens que existem entre a água mineral e a água potável comum"; "É fácil para os vendedores descreverem as diferenças e vantagens/desvantagens da água mineral" e "No momento da compra, não tenho muitas dúvidas à respeito da água mineral". Estas afirmativas correspondem às questões 5, 7, 14 e 15, respectivamente.

O nível de envolvimento foi mensurado mediante cinco itens (MITTAL, 1995): Não Importante/Importante, Não significa nada para mim/Significa muito para mim, Não me interessa/Me interessa, Não prioritário/ Prioritário, Não tem a ver comigo/Tem a ver comigo.

Os construtos acima, bem como suas respectivas questões foram representadas por uma escala do tipo likert, com valores variando de 0 a 10, tendo como âncoras as expressões "discordo totalmente" e "concordo totalmente", respectivamente. Esta escolha se deve ao fato de que é mais comum para o respondente analisar e avaliar valores em base decimal. Além disso, de acordo com Nunnaly e Bernstein (1994), para que as escalas utilizadas nesse estudo possam ser consideradas intervalares e representar um contínuo idêntico entre os valores - gradação - que elas representam, uma escala de 11 itens é preferível a uma escala de 7 itens.

\section{ANÁLISE DOS DADOS}

Neste capítulo são apresentadas as análises realizadas a partir dos resultados coletados na pesquisa.

\subsection{Tratamento dos dados e características da amostra}

As seguintes etapas foram realizadas para a análise de dados.

\subsubsection{Análise dos dados faltantes, características da amostra e análise descritiva}

O objetivo éo de identificar se as questões não-respondidas ou respondidas parcialmente pelos respondentes podem comprometer as análises a serem realizadas. Problemas como a diminuição na confiabilidade das análises estatísticas causadas pela redução do tamanho da amostra, podem ser originadas de viés na amostra estudada. Outro pressuposto importante é a aleatoriedade completamente ao acaso da amostra, onde não existe uma diferença sistemática entre os dados coletados e os dados ausentes, ou seja, ambos são um subconjunto aleatório dos elementos que compõem o universo de pesquisa (NEWTON; RUDESTAM, 1999). Primeiramente, foram verificados todos os casos em que o número de dados em branco ou preenchidos erradamente foram maior do que $10 \%$. Por conseguinte 45 questionários, do total de 318 registros, foram descartados e a amostra passou a contar com 273 casos. O próximo passo foi analisar descritivamente se alguma variável apresentou 
mais de $5 \%$ de dados faltantes, o que não ocorreu. Caso alguma variável tivesse apresentado mais do que $5 \%$ de dados ausentes, seria realizado um teste t entre os questionários nos quais a variável está ausente e presente para verificar se existe alguma diferença estatisticamente significativa (TABACHINIK; FIDEL, 2001). Por fim, foi realizado o Teste Little's MCAR. O resultado obtido foi o valor do qui-quadrado de 4738,095, com 4529 graus de liberdade e significância de 0,015, o que significa que não é possível considerar os dados ausentes completamente ao acaso e utilizar métodos de correção e imputação de dados. Assim, optou-se por trabalhar somente com casos sem dados faltantes, ficando a amostra com um total de 234 registros. Em relação às características da amostra, a grande maioria dos entrevistados são homens ( $62 \%, 145$ indivíduos) e em relação à renda, o maior grupo (19,7\%) possuía entre $\mathrm{R} \$ 1.051,00$ e $\mathrm{R} \$ 2.100,00$ de renda mensal. Obviamente, 89 mulheres tiveram os questionários validados, sendo $38 \%$ do total. Considerando a importância de cada um dos construtos, o mais importante foi a facilidade de uso, seguido das vantagens relativas, compatibilidade, capacidade de comunicar as vantagens e possibilidade de experimentar o produto. $O$ fator mais importante para consumir água mineral foi a possibilidade de consumir um produto saudável, seguido de matar a sede, ter maior qualidade de vida, praticidade e preço (economia). A grande maioria dos respondentes bebe mais água potável comum do que água mineral são cerca de $60 \%$, os que bebem mais água mineral do que água potável comum são pouco mais de $30 \%$ e os que consomem a mesma quantidade são $8,5 \%$.

\subsubsection{Normalidade}

Para verificar o padrão de distribuição das variáveis que formam os construtos e escalas estudadas, foi realizado o teste de normalidade de Kolmogorov-Smirnov. Para todas as variáveis, sem exceção o resultado foi o de significância de 0,000 , o que significa que nenhuma delas tem distribuição normal.

\subsubsection{Outliers}

No caso dos dados atípicos, optou-se por realizar o teste do cálculo da distância de Mahalanobis ( $\mathrm{D}^{2}$ de Mahalanobis), a qual compara a posição de cada elemento da amostra em relação ao centro de todas as outras variáveis, indicando desta forma, os dados atípicos multivariados. Para fazer esse cálculo, é necessário fazer a distribuição do teste qui-quadrado com o número de graus de liberdade igual ao número de indicadores - 31 - e com o nível de significância abaixo de 0,001 - 61,10 (KLINE, 2005; HAIR et al., 2009). Como resultado, os 11 casos em que o valor do $D^{2}$ de Mahalanobis for maior do que 61,10 foram considerados dados atípicos multivariados. Como não se identificou uma razão para a existência destes outliers, as análises seguintes foram realizadas a partir de amostras com e sem os outliers (234 e 223 registros, respectivamente).

\subsubsection{Unidimensionalidade}

Esta seção verifica se as escalas utilizadas para medir os construtos realmente refletem uma única dimensão (construto) ou não. Para proceder à análise, foram feitas análises fatoriais exploratórias para cada um dos construtos. A escolha do método de extração foi o de componentes principais, o qual agrupa um “número mínimo de fatores necessários para explicar a parte máxima da variância representada no conjunto original de variáveis [...]" (HAIR et al., 2009, p. 99). Como critério do método dos fatores a serem extraídos, optou-se pelo método da raiz latente, no qual o autovalor com valor igual ou maior do que 1 deve ser retido. Para facilitar a visualização e interpretação dos fatores, foram realizadas rotações ortogonais pelo método Varimax. Os primeiros resultados geraram a exclusão de quatro indicadores em virtude de baixos valores para a comunalidade: a questão 18 ("A relação custo/benefício da água mineral é positiva") do construto vantagem relativa; a questão 17 ("Beber água mineral é igual a beber a água potável comum") do construto complexidade; a questão 1 ("A água mineral é fácil de ser experimentada") do construto divisibilidade; e a questão 15 ("No momento da compra, não tenho muitas

1. Acordo que define e controla os movimentos transfronteiriços de resíduos perigosos e seu depósito. 
dúvidas à respeito da água mineral") do construto comunicabilidade. Cabe ressaltar que estes resultados são similares aos obtidos pela amostra sem os outliers.

De acordo com os resultados obtidos, os pressupostos da análise fatorial foram atendidos com os valores do teste de esferecidade de Bartlett significativos, os valores do KMO acima de 0,60 e todas as matrizes de correlação entre os itens apresentaram correlações significativas acima de 0,30 para todos os itens de todos os construtos. Novamente a diferença dos resultados das amostras com e sem dados atípicos, foram mínimas: os mesmos itens para a unidimensionalidade, todas as correlações significativas, variações abaixo de $4,3 \%$ para a variância explicada e valores de Bartlett e KMO adequados (Tabela 1).

Tabela 1 - Valores da análise fatorial exploratória para o teste de unidimensionalidade

\begin{tabular}{|c|c|c|c|c|c|c|c|}
\hline \multirow[t]{2}{*}{ Escala } & \multirow[t]{2}{*}{$\begin{array}{c}\text { Variância } \\
\text { Explicada \% }\end{array}$} & \multirow[t]{2}{*}{$\begin{array}{l}\text { Medida de } \\
\text { Adequaci- } \\
\text { dade (KMO) }\end{array}$} & \multicolumn{2}{|c|}{$\begin{array}{c}\text { Teste de } \\
\text { Esferecidade } \\
\text { de Bartlett }\end{array}$} & \multirow[t]{2}{*}{ Questões } & \multirow[t]{2}{*}{$\begin{array}{l}\text { Compo- } \\
\text { nente }\end{array}$} & \multirow[t]{2}{*}{$\begin{array}{l}\text { Comunali- } \\
\text { dade }\end{array}$} \\
\hline & & & Valor & Sig & & & \\
\hline \multirow{4}{*}{$\begin{array}{l}\text { Vantagem } \\
\text { Relativa }\end{array}$} & \multirow{4}{*}{$75,960 \%$} & \multirow{4}{*}{,686 } & \multirow{4}{*}{317,028} & & Questão 3 & 802 & ,643 \\
\hline & & & & \multirow[t]{3}{*}{,000 } & Questão 11 & ,902 & 813 \\
\hline & & & & & Questão 13 & 907 & 823 \\
\hline & & & & & Questão 2 & 825 & ,680 \\
\hline \multirow[t]{4}{*}{ Compatibilidade } & \multirow[t]{4}{*}{$66,758 \%$} & \multirow[t]{4}{*}{ 723 } & \multirow[t]{4}{*}{414,526} & \multirow[t]{4}{*}{,000 } & Questão 6 & 848 & ,720 \\
\hline & & & & & Questão 16 & ,716 &, 512 \\
\hline & & & & & Questão 20 & 871 & 758 \\
\hline & & & & & Questão 9 & ,824 & 679 \\
\hline \multirow[t]{3}{*}{ Complexidade } & \multirow[t]{3}{*}{$71,263 \%$} & \multirow[t]{3}{*}{,706 } & \multirow[t]{3}{*}{215,600} & \multirow[t]{3}{*}{,000 } & Questão 10 & ,860 & 739 \\
\hline & & & & & Questão 12 & ,848 & ,720 \\
\hline & & & & & Questão 4 & ,822 & 676 \\
\hline \multirow[t]{3}{*}{ Divisibilidade } & \multirow[t]{3}{*}{$60,774 \%$} & \multirow[t]{3}{*}{,649 } & \multirow[t]{3}{*}{109,897} & \multirow[t]{3}{*}{, 000} & Questão 8 & 747 & ,557 \\
\hline & & & & & Questão 19 & ,768 &, 589 \\
\hline & & & & & Questão 5 & 834 & 696 \\
\hline \multirow{4}{*}{$\begin{array}{l}\text { Comunicabili- } \\
\text { dade }\end{array}$} & \multirow[t]{4}{*}{$66,818 \%$} & \multirow[t]{4}{*}{ 689 } & \multirow[t]{4}{*}{163,294} & \multirow[t]{4}{*}{,000 } & Questão 7 & 821 & 674 \\
\hline & & & & & Questão 14 & 797 & 635 \\
\hline & & & & & $\begin{array}{l}\text { Importante / Não } \\
\text { Importante }\end{array}$ & ,762 & ,581 \\
\hline & & & & & $\begin{array}{l}\text { Não significa nada } \\
\text { / significa muito }\end{array}$ & 909 & ,826 \\
\hline \multirow[t]{2}{*}{ Envolvimento } & \multirow[t]{2}{*}{$74,261 \%$} & 871 & 832,793 & ,000 & $\begin{array}{l}\text { Não me interessa / } \\
\text { me interessa }\end{array}$ & 911 & 829 \\
\hline & & & & & $\begin{array}{l}\text { Não prioritário / } \\
\text { prioritário }\end{array}$ & ,848 & ,719 \\
\hline
\end{tabular}

Fonte: Dados da pesquisa

\subsubsection{Confiabilidade Interna}

Está relacionada com a capacidade da escala de gerar resultados consistentes ao longo do tempo (MALHOTRA, 2011). Isso significa que a escala deve apresentar resultados semelhantes para pessoas que possuem a mesma opinião a respeito dos diversos itens (questões) contidos nela, que, em geral, estão relacionadas a um construto simples. A existência da confiabilidade interna de um item é um pré-requisito para a validade desse construto. Contudo, medidas que não alcançam a confiabilidade interna não podem ser válidas (KLINE, 2005). O seu valor varia entre 0 e 1. Para Pestana e Gageiro (2000), o indicador de boa consistência interna deve estar acima de 0,80. Para Hair et al. (2009) valores entre 1.00 e 0.70 são aceitáveis. 
Tabela 2 - Valores de alpha de Cronbach para as escalas utilizadas na pesquisa

\begin{tabular}{|c|c|c|c|c|}
\hline Construto & $\begin{array}{l}\text { Alpha Total } \\
\text { Com Outlier }\end{array}$ & $\begin{array}{l}\text { Alpha Total Sem } \\
\text { Outliers }\end{array}$ & Itens & $\begin{array}{l}\text { Alpha se } \\
\text { Item for } \\
\text { Retirado }\end{array}$ \\
\hline \multirow{4}{*}{ Vantagem Relativa } & \multirow{4}{*}{840} & \multirow{4}{*}{849} & Questão 3 & 874 \\
\hline & & & Questão 11 & ,729 \\
\hline & & & Questão 13 & ,718 \\
\hline & & & Questão 2 & 787 \\
\hline \multirow{3}{*}{ Compatibilidade } & \multirow{3}{*}{830} & \multirow{3}{*}{852} & Questão 6 & 769 \\
\hline & & & Questão 16 & 840 \\
\hline & & & Questão 20 & ,743 \\
\hline \multirow{3}{*}{ Complexidade } & \multirow{4}{*}{,796 } & \multirow{4}{*}{833} & Questão 9 & 756 \\
\hline & & & Questão 10 & ,696 \\
\hline & & & Questão 12 & 716 \\
\hline \multirow{3}{*}{ Divisibilidade } & & & Questão 4 & ,505 \\
\hline & \multirow{2}{*}{,676 } & \multirow{2}{*}{,676 } & Questão 8 & ,631 \\
\hline & & & Questão 19 & 602 \\
\hline \multirow{4}{*}{ Comunicabilidade } & \multirow{4}{*}{,751 } & \multirow{4}{*}{,767 } & Questão 5 & 639 \\
\hline & & & Questão 7 & ,663 \\
\hline & & & Questão 14 & ,700 \\
\hline & & & Importante / Não Importante & 918 \\
\hline \multirow{4}{*}{ Envolvimento } & \multirow{4}{*}{,912 } & \multirow{4}{*}{917} & $\begin{array}{l}\text { Não significa nada / significa } \\
\text { muito }\end{array}$ & 878 \\
\hline & & & Não me interessa / me interessa & ,878 \\
\hline & & & Não prioritário / prioritário & ,896 \\
\hline & & & Não tem a ver / tem a ver & ,890 \\
\hline
\end{tabular}

Fonte: Dados da pesquisa

De acordo com esses dados, é possível observar que os valores do alpha de Cronbach são muito positivos para todas as escalas, exceto para o construto divisibilidade que apresentou um resultado um pouco abaixo do recomendável. Como a grande maioria das escalas apresentou uma pequena diferença entre os valores com e sem os dados atípicos, verifica-se que a presença de dados atípicos não interferiu fortemente na qualidade da confiabilidade interna de nenhuma das escalas analisadas. Em função dos resultados alcançados até o presente momento da pesquisa com a amostra que contém os dados atípicos, optou-se por mantê-los e realizar as todas as etapas subsequentes com esta amostra.

\subsubsection{Validade convergente}

Refere-se ao nível de correlação positiva entre os itens da escala com outras medidas do mesmo construto. Assim, duas medições do mesmo construto devem apresentar altas correlações entre as medidas, indicando que medem realmente o conceito pretendido (HAIR et al., 2009; KLINE, 2005; MALHOTRA, 2011). A utilização da análise fatorial confirmatória foi utilizada para verificação da validade convergente. Todavia, em virtude de a amostra não possuir uma distribuição normal, o modelo de estimação utilizado foi o generalized least squares (GLS), em virtude desse método, ser mais robusto ao pressuposto de violação da normalidade multivariada. Para verificar a validade convergente dos indicadores de cada construto, calculase a significância das suas cargas fatoriais em nível de $1 \%$, mediante a realização de testes $\mathrm{t}$ (os valores obtidos devem estar acima de 2,23). Além disso, se avalia a carga padronizada de cada um dos indicadores, as quais devem possuir um valor mínimo de 0,5 - o ideal são valores de 0,7 ou mais (HAIR et al., 2009). Outras duas medidas são usadas para se avaliar a validade convergente: a variância média extraída e a confiabilidade composta. Em relação à primeira, o valor aceitável é de pelo menos 0,50 para cada construto. 
Para a confiabilidade composta os valores devem ser de pelo menos 0,60 , sendo que valores acima de 0,70 são considerados bons (HAIR et al., 2009).

Tabela 3 - Valores das cargas padronizadas e dos valores dos pesos das regressões dos construtos

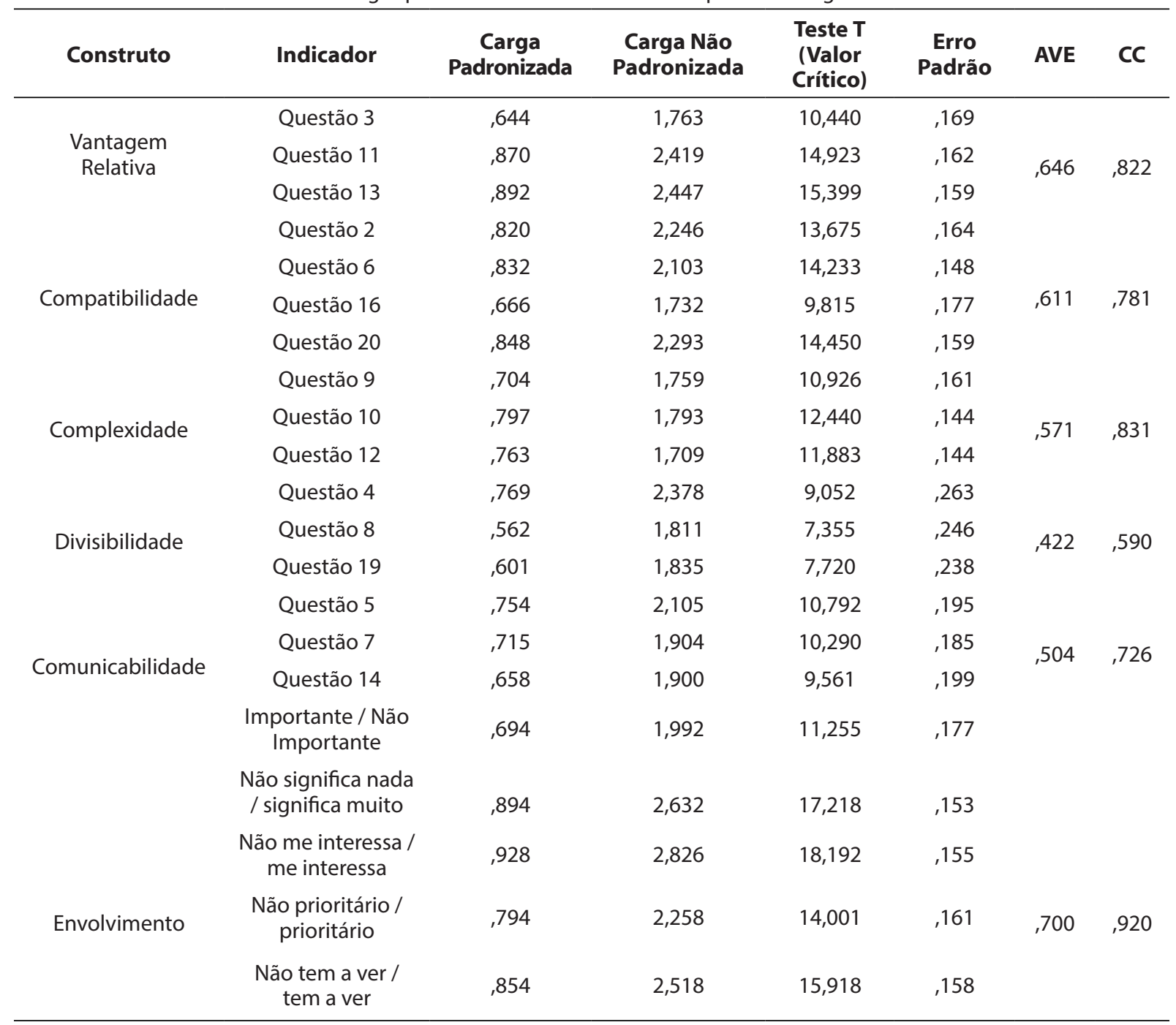

Nota: $\mathrm{AVE}=$ Variância Média Extraída. $\mathrm{CC}=$ Confiabilidade Composta

Fonte: Dados da pesquisa

Analisando-se a Tabela 3, verifica-se que todos os construtos possuem validade convergente. Somente o construto divisibilidade, apresentou resultados um pouco abaixo do adequado para a Variância Média Explicada e a Confiabilidade Composta, apesar dos valores adequados para a carga padronizada. Esse resultado é uma limitação em relação aos resultados da validade nomológica que serão apresentados mais adiante.

\subsubsection{Validade Discriminante}

A validade discriminante verifica se uma escala é distinta ou não, ou seja, identifica se os itens de uma escala não se correlacionam com outros itens de escalas diferentes. Por conseguinte, a correlação entre medidas semelhantes, mas conceitualmente diferentes deve apresentar baixa valores (HAIR et al., 2009; KLINE, 2005; MALHOTRA, 2011). Foram usados três processos para a verificação da validade discriminante: a análise fatorial confirmatória entre os pares de construtos, onde foram criados dois modelos, um com a correlação entre os construtos livre e o outro fixando a correção entre as variáveis latentes com o valor de 1, verificando-se a diferença entre os valores do qui-quadrado (se esta diferença for maior do que 3,841 - significância de 0,05 
(HAIR et al., 2009), existe a validade discriminante); o segundo processo preconiza que os valores da variância média extraída dos dois construtos devem ser maiores do que o quadrado da correlação entre eles (HAIR et al., 2009); e o terceiro processo, analisa a correlação entre os construtos, a qual não deve apresentar valores muito altos. Valores abaixo de 0,85 são indicadores da existência de validade discriminante. Considerando o critério da diferença dos qui-quadrados entre os pares de construtos livres e fixos (correção igual a 1), obteve-se a validade discriminante entre todos os construtos. No caso da correlação entre os pares de construtos, o maior valor encontrado foi de 0,715 para o par comunicabilidade e vantagem relativa. Os valores, para a maioria, das correlações entre os pares dos construtos ficaram abaixo de 0,3 . Esses valores estão dentro dos limites adequados. De outro lado, o quadrado da correlação comunicabilidade e vantagem relativa ficou acima da variância média explicada do construto comunicabilidade, sendo que o mesmo ocorreu para o quadrado da correlação do par entre comunicabilidade e divisibilidade $(0,434)$ e a variância média extraída da divisibilidade. Por conseguinte, considerando este processo, a validade discriminante foi alcançada para 19 dos 21.

\subsection{Validade nomológica}

A validade nomológica verifica se as relações, as correlações e o sentido entre os construtos presentes são significativos e condizentes com as teorias e conceitos apresentados (HAIR et al., 2009; MALHOTRA, 2011). O primeiro passo para a análise das validades nomológicas foi realizar a modelagem de equações estruturais (SEM) para os construtos mensurados. Nesta etapa da pesquisa, além de executar a SEM, verificou-se a validade dos resultados e dos modelos elaborados. De acordo com Hair et al. (2009), uma diretriz para a escolha dos índices de ajuste deve considerar a utilização de três ou quatro índices, de preferência, pelo menos um índice incremental (o qual compara o modelo testado com um modelo alternativo, em geral, um modelo nulo no qual todas as variáveis não são correlacionadas), um absoluto (o qual verifica se o modelo utilizado reproduz os dados observados) e um índice de má qualidade do ajuste (índices que verificam se o ajuste é ruim com base no valor dos resíduos ou diferenças gerados, em que valores mais altos indicam um ajuste ruim). No caso desta pesquisa, os índices do qui-quadrado, qui-quadrado normado, índice de qualidade de ajuste (GFI) e índice ajustado de qualidade de ajuste (AGFI) são medidas de ajuste absoluto. A raiz do erro quadrático médio de aproximação (RMSEA) também é uma medida de ajuste absoluto, além de ser um índice de má qualidade do ajuste. $\mathrm{O}$ índice de ajuste comparativo (CFI) é uma medida de ajuste incremental.

Tabela 4 - Índices de ajuste para a SEM com os construtos originais e estendida com o construto envolvimento

\begin{tabular}{|c|c|c|c|}
\hline Medida de Ajuste & $\begin{array}{c}\text { Valor Obtido } \\
\text { (Escala Original) }\end{array}$ & $\begin{array}{c}\text { Valor Obtido (Escala } \\
\text { Original + Envolvimento) }\end{array}$ & Valor Desejado \\
\hline Qui-quadrado & 215,23272 & 335,27842 & Não definido \\
\hline p-valor & 0,0000 & 0,0000 & Maior do que 0,05 \\
\hline Graus de liberdade & 105 & 189 & O maior possível acima de zero \\
\hline $\begin{array}{l}\text { Qui-quadrado nor- } \\
\text { malizado }\end{array}$ & 2,050 & 1,774 & $\begin{array}{c}\text { Acima de } 1 \text { até } 3 \text { e para modelos } \\
\text { complexos até } 5\end{array}$ \\
\hline CFI & 64419 & ,67262 & Acima ou igual a 0,90 \\
\hline GFI & ,89132 & ,86919 & Acima ou igual a 0,90 \\
\hline AGFI & ,84164 & ,82489 & Acima ou igual a 0,90 \\
\hline RMSEA & ,06712 & ,05763 & Entre 0,03 e 0,08 \\
\hline
\end{tabular}

Fonte: Dados da pesquisa

Analisando-se primeiramente os resultados para os indicadores de ajuste (Tabela 4), é possível verificar que os resultados para a escala original considerando somente os construtos definidos por Rogers (1983) e para a escala modificada com a inclusão do construto envolvimento são muito semelhantes. Apesar disso, as diferenças entre as duas escalas não alteraram de forma significa nenhuma avaliação dos índices de ajuste. Desse modo, é possível concluir que ambos os modelos não tem um bom nível de ajuste, considerando que somente o valor do qui-quadrado normalizado apresentou resultados dentro dos limites adequados. O GFI 
quase alcançou esses limites adequados. E os outros índices ( $p$-valor do qui-quadrado, CFI, AGFI e RMSEA) não possuem valores adequados de ajuste.

Tabela 5 - Valores e relações entre os construtos originais e estendido pelo nível de envolvimento

\begin{tabular}{ccc}
\hline Relação / Contruto & $\begin{array}{c}\text { Valor Obtido (Escala } \\
\text { Original) }\end{array}$ & $\begin{array}{c}\text { Valor Obtido (Escala Original } \\
\text { + Envolvimento) }\end{array}$ \\
\hline Comunicabilidade ---> Frequência de Uso & -03 & -17 \\
Complexidade ---> Frequência de Uso & 06 & 06 \\
Compatibilidade ---> Frequência de Uso & 03 & -09 \\
Divisibilidade ---> Frequência de Uso & -06 & -08 \\
Vantagem Relativa ---> Frequência de Uso & $37^{*}$ & $37^{*}$ \\
Envolvimento ---> Frequência de Uso & Não calculado & $23^{*}$ \\
Frequência de Uso & $15 \%$ & $16 \%$ \\
\hline
\end{tabular}

Notas: 1 ) * significativo em nível de 0,05

Fonte: Dados da pesquisa

De acordo com a Tabela 5, é possível perceber que os resultados não foram satisfatórios. Primeiramente é necessário ressaltar que os resultados obtidos para a escala original e a escala acrescida do construto envolvimento foram praticamente similares. Assim, é possível descrever que para os dois modelos de SEM realizados, a grande maioria dos construtos não apresenta uma relação significativamente com a frequência de uso da água mineral. Além disso, a variância explicada para este comportamento (beber água mineral) foi muito pequena nos dois casos, $15 \%$ e $16 \%$.

\section{CONSIDERAÇÕES FINAIS}

Apesar da escala ter apresentado bons pressupostos para a verificação da validade nomológica, os resultados não foram satisfatórios. Inicialmente, dos 20 itens que compuseram a escala aplicada à amostra, somente quatro itens de quatro fatores diferentes não apresentaram a característica da unidimensionalidade. Os valores de confiabilidade interna, validades convergente e discriminante foram satisfatórios. Todavia, os construtos não apresentaram relacionamentos significativos com a frequência de beber água mineral. Em resumo, os resultados obtidos pela escala criada e baseada na Teoria da Difusão de Inovações, não apresentou resultados satisfatórios. Outro ponto a ser considerado é que o nível de envolvimento dos respondentes não afetou os resultados, contrariando os resultados esperados de que o nível de envolvimento, seria capaz de aumentar o poder de explicação do comportamento frequente de beber água mineral.

São duas as explicações para os resultados apurados: a primeira recai principalmente em função do conteúdo dos indicadores de cada um dos construtos. Apesar dos esforços despendidos, talvez os conteúdos ainda apresentem problemas que ocorreram na primeira versão da escala. Uma outra explicação se atém à variável usada para explicar o comportamento (frequente de uso da água mineral). Pode ser que a escala seja mais poderosa para explicar o comportamento futuro do que o comportamento passado.

Em termos práticos, verifica-se que os atributos que os consumidores mais valorizam são a capacidade de matar a sede e de ser um produto saudável. Obviamente estas informações são muito úteis para a administração de marketing deste produto. Neste caso, diversas decisões sobre embalagem, rotulagem, canais e pontos de venda, comunicação de marketing e apreçamento podem ser melhor realizadas em virtude deste tipo de informação. Por exemplo: o rótulo e a embalagem podem ressaltar os aspectos saudáveis do produto, enquanto que ele deve ser vendido em locais que exista público que valoriza este aspecto, mas também em locais onde os indivíduos possam sentir sede e não tenham outra opção de se hidratar. Cabe ressaltar as características da amostra usada nesta pesquisa.

Outro ponto prático a ser considerado é referente ao comportamento de beber água mineral. Neste caso, a grande maioria dos respondentes, formados por estudantes universitários, bebe muito mais água potável comum do que a água mineral. Por isso, existe uma grande oportunidade de crescimento de 
vendas neste mercado. Por isso, novamente, a administração de marketing (4 P's) deve se ater às várias especificidades deste mercado.

Como limitação, é importante ressaltar que a amostra deste trabalho é uma amostra por conveniência. Por conseguinte, a possibilidade de generalização dos resultados é bastante limitada. Outro ponto a ser considerado diz respeito ao próprio comportamento do consumidor em relação à água mineral. Um indivíduo pode beber mais água mineral do que água potável comum, mas não tem poder de escolha (por exemplo, em casa ou no escritório). Além do mais, a comparação também poderia ocorrer em função de outros produtos, tais como sucos, refrigerantes e afins. Outro ponto a ser considerado é que a água mineral pode não ser considerada como um produto inovador por grande parte da amostra estudada.

Essa é a segunda versão da escala. Contudo, como os resultados não foram satisfatórios, será necessário revisar os itens que compõem a escala, realizar nova validade de conteúdo das escalas. O objetivo futuro é o de desenvolver um instrumento, calcado em uma teoria robusta com o intuito de aumentar a capacidade de entendimento e explicação do comportamento de consumo dos indivíduos.

\section{DEVELOPMENT OF A NEW VERSION OF MEASUREMENT SCALE OF FEATURES THAT ENCOURAGES THE ADOPTION OF NEW PRODUCTS : A STUDY ON THE MINERAL WATER}

\section{ABSTRACT}

Between 1974 and 2003, the Brazilian Institute of Geography and Statistics found that mineral water was the product with the highest growth in consumption by Brazilian families, and between 2003 and 2009 the increase reached $300 \%$. This work adheres to one of the items of Rogers model for Innovation Diffusion - innovation - which states that the factors communicability, complexity, compatibility, divisibility and relative advantage facilitate the process of adoption of new products by consumers. The aim of this study was to refine the first version of the scale of new product adoption based on the Model Innovations Diffusion, checking if it has nomological validity and measure the explained variance of individuals frequent past behavior in relation to the consumption of bottled water, besides adding the construct involvement and its influence on the model and on the refined scale. This is a descriptive study and the sample is formed by university students. The pretest was performed and yielded 318 questionnaires considered valid. After examining the data, the sample was composed of 273 cases. Despite achieving good levels of dimensionality, internal reliability, convergent and discriminant validity, only one of the constructs of the scale (relative advantage) showed a significant relationship with the frequency of mineral water intake. Despite showing a significant relationship with past behavior, the involvement construct did not alter the relations of other constructs nor the explained variance for bottled mineral water consumption.

Keywords: Product management. Innovations Diffusion Model. Scale test and development. New products adoption. Mineral water.

\section{REFERÊNCIAS}

AGGARWAL, Praveen; CHA, Taihoon; WILEMON, David. Barries To The Adoption of Really-New Products and The Role of Surrogate Buyers. The Journal of Consumer Marketing, Bradford, v.15, n. 4, p. 358-372, 1998.

AHMED, Zafar U et al. Does Country of Origin Matter for Low-involvement Products? International

Marketing Review, Bradford, v. 21, n. 1, p. 102-120, 2004.

ASSIRATI, D. M. Sumário Mineral 2013 - Água Mineral. Brasília: DPNM, 2013.

BLACKWELL, Roger D.; MINIARD, Paul W.; ENGEL, James F. Comportamento do Consumidor. São Paulo: Pioneira Thomson Learning, 2005. 
BUZZETTI, A. R. Água Mineral tem Diversidade de Embalagens. Revista Engarrafador Moderno, São Paulo, p. 38, jan./fev.1998.

CHAO, Paul; GUPTA, P. B. Information Search and Efficiency of Consumer Choices of New Cars: Country-oforigin effects. International Marketing Review, Bradford, v. 12, n. 6, p. 47-59, 1995.

CHURCHILL JR., Gilbert A. A Paradigm for Developing Better Measures of Marketing Constructs. Journal of Marketing Research, Chicago, v.16, n. 2, p. 64-73, fev. 1979.

DE TONI, D.; MILAN, G. S.; REGINATO, C. E. R. Fatores críticos para o sucesso no desempenho de novos produtos: um estudo aplicado ao setor moveleiro da Serra Gaúcha. Gestão da Produção, São Carlos, v. 18, n. 3, p. 587-602, 2011.

ETZEL, Michel J.; WALKER, Bruce J.; STANTON, William J. Marketing. São Paulo: Makron Books, 2001.

GROHMANN, M. Z. et al. Aceitação e adoção de produtos com novas tecnologias: o gênero como fator moderador. Revista de Administração e Inovação, São Paulo, v. 7, n. 4, p. 137-161, out./dez. 2010.

GUPTA, A. K.; ROGERS, E. M. Internal Marketing: Integrating R\&D and Marketing Within the Organization. The Journal of Services Marketing, Bradford, v. 5, n. 2, p. 55-68, Spring 1991.

HAIR JR., Joseph F. et al. Análise Multivariada de Dados. Porto Alegre: Bookman, 2009.

IBGE - Instituto Brasileiro de Geografia e Estatística. Em 30 anos, importantes mudanças nos hábitos de consumo dos brasileiros. [2004]. Disponível em: <http://www.ibge.gov.br/home/presidencia/ noticias/19052004pof2002html.shtm >. Acesso em: 22 jun. 2014.

KLINE, Rex B. Principals and Practice of The Structural Equation Modeling. 2. ed. New York: The Guilford Press, 2005.

MACEDO, J. A. Barros. Águas. São Paulo: Varela, 2001.

MALHOTRA, Naresh K. Pesquisa de Marketing: uma orientação aplicada. Porto Alegre: Bookman, 2011.

MITTAL, Banwari. A Comparative Analysis of Four Scales of Involviment. Psychology \& Marketing, Hoboken, v. 12, n. 7, p. 663-682, 1995.

MOURA, L. R. C. et al. Desenvolvimento e Teste de uma Escala Para Mensuração das Características Que Incentivam a Adoção de Novos Produtos: Um Estudo Sobre os Carros Bi-Combustíveis. In: Encontro de Marketing da ANPAD, 3., 2008, Curitiba. Anais.. Curitiba: ANPAD, 2008.

MOWEN, John C.; MINOR, Michael S. Comportamento do consumidor. São Paulo: Prentice Hall, 2003.

NEWTON, Rae R.; RUDESTAM, Kjell E. Your Statistical Consultant: Answer To Your Research \& Data Analysis Questions. Reino Unido: Sage-UK, 1999.

NUNNALY, J.C.; BERNSTEIN, I. H. Psychometric Theory. New York: McGraw-Hill, 1994.

PAREDES, B. J. B.; SANTANA, G. A.; FELL, A. F.de A. Um Estudo de Aplicação do Radar da Inovação: o grau de inovação organizacional em uma empresa de pequeno porte do setor metal-mecânico. Navus - Revista de Gestão e Tecnologia, Florianópolis, v. 4, n. 1, p. 76-88, jan./jul. 2014. 
PESTANA, João N.; GAGEIRO, Maria H. Análise de dados para ciências sociais: a complementariedade do SPSS. Lisboa: Sílabo, 2000.

PETER, J. PAUL; OLSON, Jerry C. Consumer Behavior and Marketing Strategy. New York: Irwin/McGraw-Hill, 1999.

ROGERS, E. M. Diffusion of Innovations. New York: The Free Press, 1983.

ROGERS, E. M. et al. Complex Adaptive Systems and the Diffusion of Innovations. The Innovation Journal: The Public Sector Innovation Journal, Newark, v. 10, n. 3, article 29, 2008.

SHETH, Jagdish N.; MITTAL, Banwari; NEWMAN, Bruce I. Comportamento do cliente: indo além do comportamento do consumidor. São Paulo: Atlas, 2001.

SOLOMON, Michael R. O comportamento do consumidor: comprando, possuindo e sendo. Porto Alegre: Bookman, 2002.

TABACHINIK, B. G.; FIDELL, L. S. Using Multivariate Statistics. 4. ed. New York: HarperCollins, 2001.

TERRES, M. da S. et al. O Papel da Confiança na Marca na Intenção de Adoção de Novas Tecnologias. Revista de Administração e Inovação, São Paulo, v. 7, n. 4, p.162-185, out ./dez. 2010.

URDAN; A. T.; OSAKU, W. A. Determinantes do Sucesso de Novos Produtos: Um Estudo de Empresas Estrangeiras no Brasil. In: Encontro Anual da Associação Nacional de Pós-Graduação e Pesquisa em Administração, 29., 2005, Brasília. Anais do XXIX ENANPAD. Brasília: ANPAD, 2005.

VERÃO atípico reforça tendência do crescimento do setor de Água Mineral. Água \& Vida. São Paulo, v. 15, n. 81, p. 17, mar./abr. 2014.

ZAICHKOWSKY, Judith L. Measuring the Involvement Construct. Journal of Consumer Research, Chicago, v. 12, p. 341-352, dez. 1985.

ZAICHKOWSKY, Judith L. Conceptualizing Involvement. Journal of Advertising, Los Angeles, v. 15, n. 2, p. 4-15, 1986.

ZAICHKOWSKY, Judith L. The Emotional Aspect of Product Involvement. Advances In Consumer Research, Chelsea, v. 17, n. 1, p. 616-618, 1990. 